\title{
Pharmacoeconomic Analysis of Hemophilia Care in Romania
}

\author{
Petre Serban ${ }^{1}$, Brigitha Vlaicu ${ }^{1}$, Margit Serban ${ }^{2}$, Cristina Emilia Ursu ${ }^{2, * \mathbb{D}}$, Adina Traila ${ }^{3}$, \\ Cristian Jinca ${ }^{4}$, Jenel Marian Patrascu ${ }^{5}$, Daniel Andrei ${ }^{6}$, Andrei Kozma ${ }^{7}$ and \\ Teodora Smaranda Arghirescu 4
}

1 Department 14, Center for Preventive Medicine Studies, Victor Babes University of Medicine and Pharmacy Timisoara, 300041 Timisoara, Romania; serban_petry@yahoo.com (P.S.); vlaicu@umft.ro (B.V.)

2 Romanian Academy of Medical Sciences, Onco-Hematology Research Unit, Children Emergency Hospital "Louis Turcanu" Timisoara, European Hemophilia Treatment Centre, 300011 Timisoara, Romania; mserban@spitalcopiitm.ro

3 Medical Centre for Evaluation Therapy, Medical Education and Rehabilitation of Children and Young Adults, European Hemophilia Treatment Centre, 305100 Buzias, Romania; adinatraila@yahoo.com

4 Department of Pediatrics, Division of Onco-Hematology, Victor Babes University of Medicine and Pharmacy Timisoara, 300041 Timisoara, Romania; cristian_jinca@yahoo.com (C.J.); sarghirescu@yahoo.com (T.S.A.)

5 Department of Orthopedics, Victor Babes University of Medicine and Pharmacy Timisoara, 300041 Timisoara, Romania; jenelmarianp@yahoo.com

6 Romanian Hemophilia Association, 300011 Timisoara, Romania; danielandrei07@gmail.com

7 Research Department in Social Paediatrics and Obstetrics, “Alessandrescu-Rusescu”, National Institute for Mother and Child Health, 020395 Bucharest, Romania; dr.ka.mailbox@gmail.com

* Correspondence: emiliaursu@gmail.com or emiliaursu@spitalcopiitm.ro; Tel.: +40-7-2436-2729

Received: 7 November 2020; Accepted: 10 December 2020; Published: 18 December 2020

\begin{abstract}
Hemophilia, a congenital X linked disease, has the serious burden of bleeding, requiring life-long replacement with coagulation factors (CF). In the present day, there is a continuously improving treatment for this condition. Objective: Our observational, cross-sectional study aims at finding out whether a prophylactic replacement with $\mathrm{CF}$ is affordable from the point of view of its cost-effectiveness in our country. Material and methods: A cohort of 122 persons with hemophilia were included in this patient-reported outcome survey, and they answered a questionnaire consisting of 56 items, focused on 4 domains-socio-demographic, medical, quality of health/life and cost/cost-effectiveness. Results and discussion: The markers for quality of health/life were correlated with the direct and indirect costs of care, comparing subgroup 1 of patients with prophylactic vs. subgroup 2 with on-demand replacement. Based on the incremental quality adjusted life years and the incremental costs, we calculated the incremental cost-effectiveness ratio (ICER) proving that prophylaxis is more cost-effective than on-demand replacement on a long time basis. Conclusions: The ICER is a threshold recommending the reimbursement of costs for a life-long prophylactic replacement in our country.
\end{abstract}

Keywords: hemophilia; socio-economic burden; ICER

\section{Introduction}

Hemophilia is a monogenic $\mathrm{X}$-linked hereditary bleeding disorder, characterized by the deficiency of coagulation factor VIII (hemophilia A-HA) or IX (hemophilia B-HB), demanding for therapeutic control a lifelong replacement with these factors. Hemophilia belongs to the large group of rare diseases, but it is fortunately experiencing a continuously improving treatment, able today to ensure a "functional cure" [1]. 
In the previous decades pharmaceutical companies registered significant progress, succeeding in bringing into use, beside safe plasma derived (pd) coagulation factor concentrates (CFC), other recombinant factors $(\mathrm{rF})$. Successively, there was a first, second, third and fourth generation, followed today by extended half-life factors (EHLF) or recently non-factor products, paving the way for the "new golden era" of hemophilia. Prophylaxis, consisting of $2-4$ weekly intravenous administrations of CFC allows persons with hemophilia $(\mathrm{PwH})$ to benefit from a close to normal life expectancy and life quality, avoiding life-threatening bleeding and degenerative disabling arthropathies [2-4]. The availability and accessibility of these medicines has been solved; only the assurance of their affordability remains as an important goal, depending on the economic potential of each country $[5,6]$. These are the main determinants of the quality of care deciding the treatment regimen: regular prophylaxis (RP) with preventive replacement at least 45 weeks/year, short term prophylaxis (STP) with intermittent preventive replacement, not more than 45 weeks/year and on-demand (OD) with episodic treatment for bleeding events.

In Romania, the replacement therapy with CFC has begun rather late (1997), and OD has been performed with low dosages; only recently (2016-2017) could we register a turning point in our hemophilia care, with a significant increase ( 2.5 times more) of its dedicated budget. The RP replacement has been initiated for the severe/moderate with severe phenotype forms of disease of $\mathrm{PwH}$ under the age of 18 years, extensible to those who are older, but who have already experienced this type of replacement and STP recommended for special conditions for all ages.

The advantage of prophylaxis versus OD therapy has been repeatedly proved in randomized controlled clinical studies. Despite the acceptance of the reality that prophylaxis is the standard of care, the high economic burden of missing it in the situation of limited resources is responsible for treating only $25-30 \%$ of $\mathrm{PwH}$ in the world [7]. Therefore, it is highly recommended that decision makers, together with Health Technology Assessments (HTA) agencies, undertake some ranking of medicines/interventions for more efficient reimbursement policies. Under this approach, assessments of value for money are undertaken by comparing the incremental costs with the incremental benefits. Such economic evaluations are becoming established internationally, being especially important in the field of rare disorders, implicitly in hemophilia. With a consumption of less than 4 IU F VIII and $0.5 \mathrm{IU} / \mathrm{capita} /$ year respectively we continue to remain among the European countries with the lowest level of therapy, under our economical affordability [6,7].

In this situation, we wanted to have an insight in the real life of $\mathrm{PwH}$ in our country $[8,9]$ and to see what is reasonable and achievable to be performed in order to give $\mathrm{PwH}$ similar opportunities for treatment as they have in rest of Europe. Confronted with the present situation with significant improvement of outcomes of $\mathrm{PwH}$ with $\mathrm{RP}$, but also facing the high competition of hemophilia for the financial support with many other disorders, with the concern of losing the access to an appropriate therapy, we decided to undertake a cost-effectiveness study of hemophilia care in our country aiming at exploring the societal economic burden in order to find a reasonable, affordable solution, based on the medical, humanitarian and socio-economic principles of medical care [10].

\section{Study Design}

It is a cross-sectional observational study of people with severe ( $\mathrm{CF}<1 \%$ of normal) or moderate (CF $1-5 \%$ of normal) form with severe phenotype of hemophilia and its related von Willebrand diseases (vWD), diagnosed and treated in 11 surrounding counties from the Western part of Romania with an acceptance rate of $62.4 \%$. From a total number of $296 \mathrm{PwH}, 122$ patients were included. They were recruited thanks to the collaboration of the Romanian Hemophilia Patients Association and assisted by their care-providers. We used a patient reported outcomes (PRO) model of survey, based on a specific questionnaire administered by e-mail or post, a similar questionnaire being administered to an age and sex matched control group of 136 persons [11]. This captured retrospective data of a time interval of 12 months (1 January 2019-31 December 2019), and the study was carried out between April 2020 and July 2020. All participants expressed their informed consent to attend the study and 
the Institutional Ethics Committee of the European Hemophilia Treatment Centers Buzias/Timisoara approved its performance.

\section{Objectives}

There are significant discordances across European countries, between the consumption of CFC (expressed in IU/capita/year) and their economic status. The great majority are exceeding and over-performing the usage, while our country is belonging to the very small number of countries that are under-performing in this respect, remaining as the country with the lowest consumption, under our financial affordability. This motivated us to undertake this study, with a desire to contribute to arguments for the improvement of hemophilia care in our country, in the hope to be a model for other countries that are in a similar situation like us. Our study was focused on 2 subgroups of patients with different therapy regimens, mainly with OD or mainly with prophylactic replacement (PR), having 3 objectives: to estimate the economic costs related to hemophilia and vWD care from a societal perspective, to assess the quality of health and of quality of life (QoL) of patients and to compare the cost-effectiveness of the treatment in the 2 subgroups in two scenarios (real and bodyweight adjusted consumption of CFC) aiming the estimation of incremental cost-effectivity ratio (ICER) in connection with incremental quality adjusted life years (QALY).

\section{Patients and Methods}

The study population is a cohort of 122 patients with severe (115) and moderate with severe phenotype (7) of HA (92), HB (16) and severe form of vWD (14), excluded patients were those with mild ( $\mathrm{CF}>5 \%$ of normal) forms of disease. The sample was divided in 2 subgroups: subgroup 1 , consisting of 39 patients born after 1997 with a history of replacement therapy since their early childhood, at present with RP (76.92\%) or STP (15.38\%) and subgroup 2 of 83 patients born before 1997, the year when replacement therapy was introduced in our country, lacking this treatment for a period, and at present predominantly (39.76\%) with on-demand treatment (OD) (Table 1$)$.

The study was based on a comprehensive questionnaire, administered to the patients, consisting of 56 items, for recording appropriate information on 4 domains: socio-demographic (9), medical (31), quality of health and life (10) and costs/cost-effectiveness of treatment (6); a similar questionnaire without the medical information was administered to the control group.

For the economic evaluation, the following parameters were considered for direct medical costs: specific medicines (CFC and by-passing agents-BPA), biological and imagistic assessments (ultrasonography, magnetic resonance imaging, computed tomography, radiography) for diagnosis and monitoring, hospital admission and ambulatory bleed related activity whereas for indirect costs: healthcare transport, social support and services for handicap, sick leave, early medical retirement and labor productivity losses. All data regarding the real costs were sourced from the administrative departments of the treating clinics and from publicly available data; in order to be comparable with the dates from other countries we also established costs/capita/year, all expressed in national currency exchanged in $€$ at the present rate $(1 €=4.85$ LEI) $[10,11]$.

For evaluation of health quality surrogate markers like annualized bleeding rate (ABR), annualized joint bleeding rate (AJBR), target joints, need of invasive orthopedic interventions and surgery for life threatening bleeds were used; much attention was dedicated to the impact of treatment on the hemophilia-related secondary morbidity: mainly chronic hemarthropathy, an important driver of budget consumption, neutralizing inhibitors of F VIII or IX and bloodborne infections, like hepatitis C or $\mathrm{B}$, and HIV infection $[12,13]$. 
Table 1. Characteristics of the patients in subgroup (1) and (2).

\begin{tabular}{|c|c|c|c|}
\hline Variables & Subgroup 1 (39) & Subgroup 2 (83) & $p$ Value \\
\hline Age (years) $(X \pm D S)$ & $11.3 \pm 6.51$ & $39.7 \pm 10.79$ & $<0.001$ \\
\hline $\mathrm{BW}(\mathrm{X} \pm \mathrm{DS})$ & $38.87 \pm 27.02$ & $79.91 \pm 17.98$ & $<0.001$ \\
\hline HA-moderate-severe & $1(2.56 \%) 25(64.10 \%)$ & $4(4.82 \%) 62(74.70 \%)$ & $0.1<0.001$ \\
\hline HB-moderate-severe & $1(2.56 \%), 7$ (17.95\%) & $1(1.21 \%), 7$ (8.43\%) & - \\
\hline vWD-severe & $5(12.82 \%)$ & $9(10.84 \%)$ & $<0.01$ \\
\hline $\begin{array}{l}\text { Therapeutic regimen } \\
\text {-OD } \\
\text {-STP } \\
\text {-RP }\end{array}$ & $\begin{array}{l}3(7.69 \%) \\
6(15.38 \%) \\
30(76.92 \%)\end{array}$ & $\begin{array}{l}33(39.76 \%) \\
43(51.81 \%) \\
7(8.43 \%)\end{array}$ & $\begin{array}{l}<0.001 \\
<0.001 \\
<0.001\end{array}$ \\
\hline $\begin{array}{l}\text { Age at start of } \\
\text { replacement (years) }\end{array}$ & $2.22 \pm 1.88$ & $18 \pm 10.69$ & $<0.01$ \\
\hline ABR-RP & $2.84(2.56-2.97)$ & $15.25(14.95-15.55)$ & $<0.001$ \\
\hline AJBR-RP & $1.15(1.15-1.25)$ & $12.75(12.15-13.05)$ & $<0.001$ \\
\hline ABR-STP & $4.0(3.5-4.5)$ & $13.90(13.50-14.50)$ & $<0.001$ \\
\hline AJBR-STP & $3.42(2.95-3.92)$ & $10.27(9.90-10.95)$ & $<0.001$ \\
\hline ABR-OD & 7.33 (6.55-7.95) & $18.31(17.90-18.95)$ & $<0.001$ \\
\hline AJBR-OD & $6.67(6.05-7.05)$ & $14.06(13.56-14.67)$ & $<0.001$ \\
\hline $\begin{array}{l}\text { Patients with chronic } \\
\text { hemarthropathy } \\
\text { Poliarticular chronic } \\
\text { hemarthropathy }\end{array}$ & $\begin{array}{l}8(20.51 \%) \\
5(12.82 \%)\end{array}$ & $\begin{array}{l}58(69.88 \%) \\
58(69.88 \%)\end{array}$ & $\begin{array}{l}<0.001 \\
<0.001\end{array}$ \\
\hline $\begin{array}{l}\text { Patients with target joints } \\
\text { Poliarticular target joints }\end{array}$ & $\begin{array}{l}7(17.95 \%) \\
3(7.69 \%) \\
\end{array}$ & $\begin{array}{l}46(55.42 \%) \\
34(40.96 \%) \\
\end{array}$ & $\begin{array}{l}<0.001 \\
<0.001\end{array}$ \\
\hline $\begin{array}{l}\text { Invasive intervention } \\
\text {-orthopedic } \\
\text {-non-orthopedic surgery }\end{array}$ & $\begin{array}{l}0 \\
0\end{array}$ & $\begin{array}{l}9(10.84 \%) \\
4(4.81 \%)\end{array}$ & $\begin{array}{l}0.001 \\
<0.01\end{array}$ \\
\hline $\begin{array}{l}\text { Inhibitors-total } \\
\text {-OD } \\
\text {-STP } \\
\text {-RP }\end{array}$ & $\begin{array}{l}5(12.82 \%) \\
5(12.82 \%)\end{array}$ & $\begin{array}{l}10(12.05 \%) \\
5(6.02 \%) \\
3(3.61 \%) \\
2(2.41 \%)\end{array}$ & $<0.001$ \\
\hline Infection with HBV & 0 & $4(4.82 \%)$ & $<0.01$ \\
\hline Infection with HCV & 0 & $38(45.78 \%)$ & $<0.001$ \\
\hline Infection with HIV & 0 & 0 & 0 \\
\hline Quality of life (EQ-VAS) & $0.84 \pm 0.19$ & $0.63 \pm 0.14$ & 0.01 \\
\hline Deficiency & $9(23.07 \%)$ & $34(40.96 \%)$ & 0.01 \\
\hline Disability & 0 & $31(37.35 \%)$ & 0.001 \\
\hline Handicap & 0 & $18(21.68 \%)$ & 0.001 \\
\hline
\end{tabular}

(BW—body weight, HA—hemophilia A, HB-hemophilia B, vWD—von Willebrand disease, ABR—annualized bleeding rate, AJBR—annualized joint bleeding rate, $\mathrm{RP}$ - regular prophylaxis, $\mathrm{OD}$ - on-demand, STP—short term prophylaxis, $\mathrm{HBV}$-hepatitis B virus, $\mathrm{HCV}$-hepatitis $\mathrm{C}$ virus, HIV-human immunodeficiency virus, EQ-VAS-EuroQol-visual analogue scale).

In connection with quality of health, quality of life (QoL) was evaluated using generic instruments, based on self-estimation, easily administered and largely used in hemophilia assessments: EQ-5D-VAS, aiming at receiving an insight in 5 domains: mobility, self-care, usual activities, pain/discomfort and anxiety/depression. Additionally, the International Classification of Functioning (ICF) classification of 
World Health Organization (WHO) for the estimation of function and participation of our patients was used [14].

Special attention was dedicated for the evaluation of cost-effectiveness of treatment comparatively in the two subgroups, defined by their different treatment regimens, calculating the incremental costs, the incremental QALYs, costs/QALY and the ICER. For the ICER calculation we used a long-term perspective of 30 years and the present real-life expectancy for male persons in our country and discounted it by $15 \%$ for hemophiliacs under our treatment conditions $[15,16]$.

The social impact (academic performance, familial, professional and social status) of hemophilia care was analyzed in comparison with the control group (Table 2).

Table 2. Social impact of hemophilia on $\mathrm{PwH}$.

\begin{tabular}{llll}
\hline \multicolumn{1}{c}{ Variables } & \multicolumn{1}{c}{ Study Subgroup 2 (83) } & Control Group (136) & $p$ Value \\
\hline Age X \pm DS (years) & $40 \pm 10.69$ & $37 \pm 14.38$ & $>0.05$ \\
\hline Academic performance & & & \\
Elementary School & $7(8.43 \%)$ & $6(4,44 \%)$ & $>0.1$ \\
Vocational school & $12(14.46 \%)$ & $9(6.62 \%)$ & $<0.01$ \\
High school & $22(26.51 \%)$ & $50(36.76 \%)$ & $<0.01$ \\
Faculty & $22(26.51 \%)$ & $67(49.26 \%)$ & $<0.001$ \\
Others & $2(2.41 \%)$ & $7(5.14 \%)$ & $>0.1$ \\
\hline Marital status & & & $<0.001$ \\
Married & $31(37.35 \%)$ & $82(60.29 \%)$ & $<0.001$ \\
Divorced & $29(34.94 \%)$ & $7(5.14 \%)$ & $<0.001$ \\
Single & $4(4.82 \%)$ & $36(26.47 \%)$ & $<0.001$ \\
\hline Professional status & & & $<0.001$ \\
Qualified worker & $10(12.82 \%)$ & $22(16.17 \%)$ & $<0.001$ \\
Unqualified worker & $1(1.28 \%)$ & $19(13.97 \%)$ & $<0.001$ \\
Office clerk & $8(10.26 \%)$ & $28(20.58 \%)$ & \\
Specialist with higher education & $2(2.56 \%)$ & $10(7.35 \%)$ & $<0.01$ \\
\hline Social status & & & $<0.001$ \\
Retired & 0 & $4(2.94 \%)$ & $<0.001$ \\
Sick retiree & $10(12.05 \%)$ & 0 & - \\
Socially assisted disability & $39(46.98 \%)$ & $1(0.73 \%)$ & $<0.001$ \\
Unemployed & 0 & $1(0.73 \%)$ & $<0.001$ \\
Pupils/students & $3(3.61 \%)$ & $23(16.91 \%)$ & $<0.001$ \\
Others & $5(6.02 \%)$ & $14(10.29 \%)$ & \\
No. absences-school/service & $14(16.87 \%)$ & $8(5.88 \%)$ & 1001 \\
-No. persons & 625 & & \\
-days/person & & & \\
\hline
\end{tabular}

We were aware of the bias in calculating real CFC costs, representing $98.5 \%$ and $91.5 \%$ of direct and total costs, respectively. The consumption of CFC is directly correlated with the body-weight (BW) of the patients, the dosage being calculated in IU $/ \mathrm{kg} \mathrm{BW}$, or there is an obvious discrepancy between the two subgroups considering their average weight. We wished to eliminate this limit for obtaining a correct term for comparison and prediction by calculating individually also a BW adjusted costs of medication.

Statistical analysis was performed using Microsoft Office Excel 2013 and SPSS 14.0 for Windows Evaluation Version, calculating average and standard deviation with significance at $p<0.05$ and correlation coefficient significant when $r>0.4$.

\section{Results}

Our results were correlated with patient characteristics, mainly focused on the treatment history, specific for each subgroup (Tables 3 and 4) looking for the distribution of direct and indirect costs. 
Table 3. Distribution of our real direct costs/patient/year (EUR).

\begin{tabular}{lllllll}
\hline & \multicolumn{2}{l}{ Total Group (122) } & \multicolumn{2}{l}{ Subgroup 1 (39) } & \multicolumn{2}{l}{ Subgroup 2 (83) } \\
\cline { 2 - 7 } & Sum & Per Capita & Sum & Per Capita & Sum & Per Capita \\
\hline $\begin{array}{l}\text { Specific } \\
\text { medication }\end{array}$ & $8,284,770.31$ & $67,907.95$ & $3,054,449.48$ & $78,319.21$ & $5,230,320.82$ & $63,015.91$ \\
\hline $\begin{array}{l}\text { Diagnosis and } \\
\text { monitoring }\end{array}$ & $26,802.06$ & 219.68 & $8,615.46$ & 220.90 & $18,186.00$ & 219.11 \\
\hline Hospitalization & $91,231.30$ & 747.79 & $29,912.00$ & 766.90 & $61,319.38$ & 738.78 \\
\hline Total costs & $8,402,803.67$ & $68,875.42$ & $3,092,876.94$ & $79,307.09$ & $5,309,826.20$ & $63,973.81$ \\
\hline
\end{tabular}

Table 4. Distribution of our real indirect costs/patient/year (EUR).

\begin{tabular}{lllllll}
\hline & \multicolumn{2}{l}{ Total Group (122) } & \multicolumn{2}{l}{ Subgroup 1 (39) } & \multicolumn{2}{l}{ Subgroup 2 (83) } \\
\cline { 2 - 7 } & Sum & Per Capita & Sum & Per Capita & Sum & Per Capita \\
\hline Transport & $43,772.37$ & 358.78 & $18,058.55$ & 463.04 & $25,713.80$ & 309.80 \\
\hline Social support & $18,321.60$ & 150.14 & 3112.50 & 79.81 & $15,209.00$ & 183.24 \\
\hline Loss of productivity & $586,587.00$ & 4808.09 & $20,582.00$ & 527.74 & $566,005.00$ & 6819.33 \\
\hline Total costs & $648,680.97$ & 5317.01 & $41,753.05$ & 1070.59 & $606,927.80$ & 7312.37 \\
\hline
\end{tabular}

Additionally, in order to have an insight into the potential future costs of patients, now belonging to subgroup 1, reaching the age of adolescents and adults, we also calculated the BW adjusted costs for medication (Table 5), for direct and total costs (Tables 5 and 6).

Table 5. Distribution of the BW-adjusted direct costs/patient/year (EUR).

\begin{tabular}{lllllll}
\hline & \multicolumn{2}{l}{ Total Group (122) } & \multicolumn{2}{l}{ Subgroup 1 (39) } & \multicolumn{2}{l}{ Subgroup 2 (83) } \\
\hline & Sum & Per Capita & Sum & Per Capita & Sum & Per Capita \\
\hline $\begin{array}{l}\text { Specific } \\
\text { medication }\end{array}$ & $11,491,942.25$ & $94,196.25$ & $6,261,621.43$ & $160,554.38$ & $5,230,320.82$ & $63,015.91$ \\
\hline $\begin{array}{l}\text { Diagnosis and } \\
\text { monitoring }\end{array}$ & $26,802.06$ & 219.68 & 8615.46 & 220.90 & $18,186.00$ & 219.11 \\
\hline Hospitalization & $91,231.30$ & 747.79 & $29,912.00$ & 766.90 & $61,319.38$ & 738.78 \\
\hline Total costs & $11,609,975.61$ & $95,163.72$ & $6,300,148.89$ & $161,542.18$ & $5,309,826.20$ & $63,973.81$ \\
\hline
\end{tabular}

Table 6. Distribution of BW-adjusted direct and total costs/patient/year (EUR).

\begin{tabular}{lllllll}
\hline & \multicolumn{2}{l}{ Total Group (122) } & \multicolumn{2}{l}{ Subgroup 1 (39) } & \multicolumn{2}{l}{ Subgroup 2 (83) } \\
\hline & Sum & Per Capita & Sum & Per Capita & Sum & Per Capita \\
\hline Direct costs & $11,609,975.61$ & $95,163.72$ & $6,300,148.89$ & $161,542.18$ & $5,309,826.20$ & $63,973.81$ \\
\hline Indirect costs & $648,680.97$ & $5,317.01$ & $41,753.05$ & $1,070.59$ & $606,927.80$ & $7,312.37$ \\
\hline Total costs & $12,258,656.58$ & $100,480.73$ & $6,341,901.94$ & $162,612.77$ & $5,916,754.00$ & $71,286.18$ \\
\hline
\end{tabular}

The comparative distribution of the real and BW-adjusted annual total, direct and indirect costs/patient is presented in (Table 7). 
Table 7. Comparative distribution of the real and the BW-adjusted direct and indirect costs /patient/year and their proportion from the total costs (EUR).

\begin{tabular}{ccccccc}
\hline \multirow{2}{*}{ Variable } & \multicolumn{2}{c}{ Total Group (122) } & \multicolumn{2}{c}{ Subgroup 1 (39) } & \multicolumn{2}{c}{ Subgroup 2 (83) } \\
\cline { 2 - 7 } & Real & BW Adjusted & Real & BW Adjusted & Real & BW Adjusted \\
\hline Direct costs (Euro) & $68,875.4$ & $95,163.72$ & $79,307.00$ & $161,542.18$ & $63,973.8$ & $63,973.8$ \\
\hline$\%$ & 92.83 & 94.71 & 98.67 & 99.34 & 89.74 & 89.74 \\
\hline Indirect costs (Euro) & $5,317.00$ & $5.317,00$ & 1070.6 & 1070.6 & 7312.4 & 7312.4 \\
\hline$\%$ & 7.17 & 5.29 & 1.33 & 0.66 & 10.26 & 10.26 \\
\hline Total costs (Euro) & $74,192.4$ & $100,480.73$ & $80,377.6$ & $162,612.77$ & $71,286.2$ & $71,286.2$ \\
\hline \multicolumn{7}{c}{ (BW-body weight). }
\end{tabular}

The largest costs consumption was dedicated for the specific replacement therapy consisting of CFC including BPA (Table 8).

Table 8. Real and BW-adjusted costs of medication/patient/year and their proportion from direct and total costs (EUR).

\begin{tabular}{lccccc}
\hline & CFC Costs & Direct Costs & \% & Total Costs & \% \\
\hline Real cost & $67,907.95$ & $68,875.42$ & 98.58 & $74,192.40$ & 91.52 \\
\hline BW adjusted costs & $94,196.25$ & $95,163.72$ & 98.98 & $100,480.73$ & 93.74 \\
\hline Subgroup 1 & & & & & \\
- real cost & $78,319.21$ & $79,307.09$ & 98.75 & $80,377.60$ & 97.43 \\
- BW adjusted costs & $160,554.38$ & $161,542.18$ & 99.38 & $162,612.77$ & 98.73 \\
\hline Subgroup 2 & & & & & \\
- real cost & $63,015.91$ & $63,973.81$ & 98.5 & $71,286.20$ & 88.39 \\
- BW adjusted costs & $63,015.91$ & $63,973.81$ & 98.5 & $71,286.20$ & 88.39 \\
\hline
\end{tabular}

(BW-body weight, CFC—coagulation factor concentrates).

The financial impact of orthopedic interventions for chronic pain, disabling chronic hem-arthropathy, expression of the principal hemophilia therapy-related secondary morbidity, is illustrated in Table 9. Inhibitors, the other considered most important secondary morbidity, is high budget consuming, as it is evident also on the same table, containing also BW-adjusted CFC costs (Table 9), mentioning that the only subject with inhibitors undergoing surgery was a child with cheilognathopalatoschisis with a BW of $7 \mathrm{~kg}$.

Table 9. Distribution of the real costs in invasive procedures patient/year (EUR) in invasive surgery and the impact on costs of inhibitors development.

\begin{tabular}{lllll}
\hline & $\begin{array}{l}\text { Costs for } \\
\text { Investigations }\end{array}$ & $\begin{array}{l}\text { Costs for Factor } \\
\text { Concentrate/ Intervention }\end{array}$ & $\begin{array}{l}\text { Costs for Medical } \\
\text { Devices/ } \\
\text { Intervention }\end{array}$ & $\begin{array}{l}\text { Total Cost/ } \\
\text { Patient/ } \\
\text { Intervention }\end{array}$ \\
\hline PwH without inhibitors & $2798.93 \pm 503.2$ & $169,370.45 \pm 104,235.33$ & $9596.07 \pm 6,985.8$ & $181,765.45$ \\
\hline PwH with inhibitors (real costs) & $2,878.00$ & $155,732.9$ & $10,002.59$ & $168,613.49$ \\
\hline $\begin{array}{l}\text { PwH with inhibitors (BW } \\
\text { adjusted costs) }\end{array}$ & $28,780.00$ & $1,557,329.0$ & $100,025.90$ & $1,686,134.9$ \\
\hline
\end{tabular}

(PwH—persons with hemophilia, BW—body weight).

The third hemophilia treatment-related secondary morbidity is represented by bloodborne infections; the proportion of $\mathrm{HBV}(3.27 \%)$ and HCV (31.15\%) was high in subgroup 2, fortunately without HIV contamination. Missing the costs of their diagnosis, monitoring and treatment, we could not introduce them in our calculations. 
Regarding the proportion of indirect costs, a meaningful issue reflecting additional costs mainly generated by all the hemophilia-related secondary morbidity above-mentioned was $7.17 \%$ for the whole group of patients, reaching in contrast to subgroup $1(1.33 \%) 10.26 \%$ in subgroup 2 , as presented in Table 7.

We considered the evaluation of cost-effectiveness to be very important for our analysis. The comparative evaluation of the increment of QoL and its consequence, the QALYs and the increment of costs in the two subgroups, was the support for calculation of the ICER on a time horizon of 30 years. The ICER resulted was only slightly in favor of the subgroup 1. However, in order to exclude the bias related to the important discordance of the BW of patients in the two groups, we calculated the costs of CFC also for the BW adjusted consumption. In real life, but at the same time also in the scenario with adjusted costs to BW, we assessed an ICER (1082.30 and 10,878.10, respectively), with values that are under the threshold for reimbursement, being less than one GDP/capita/year for our country; the reimbursement with ICER $<2-3$ GDP/capita/year is generally considered acceptable. Consequently, we can conclude that maintaining of prophylactic regimen is affordable for the patients from subgroup 1 even later, in their adulthood (Tables 10 and 11).

Table 10. Cost/QALYs and parameters of cost-effectiveness evaluation with our present real costs/patient/ year (EUR).

\begin{tabular}{|c|c|c|c|c|c|c|}
\hline & Total Costs & QALYs & $\begin{array}{l}\text { Incremental } \\
\text { Costs }\end{array}$ & $\begin{array}{c}\text { Incremental } \\
\text { QALYs }\end{array}$ & Cost/QALYs & ICER \\
\hline Subgroup 2 (83) & $71,286.2$ & 25.2 & \multirow{2}{*}{9091.29} & \multirow{2}{*}{8.4} & 2828.88 & \multirow{2}{*}{1082.30} \\
\hline Subgroup 1 (39) & $80,377.49$ & 33.6 & & & 2392.19 & \\
\hline
\end{tabular}

Table 11. Parameters of cost-effectiveness evaluation with BW adjusted costs/patient/year (EUR).

\begin{tabular}{|c|c|c|c|c|c|c|}
\hline & Total Costs & QALYs & $\begin{array}{c}\text { Incremental } \\
\text { Costs }\end{array}$ & $\begin{array}{c}\text { Incremental } \\
\text { QALYs }\end{array}$ & $\begin{array}{c}\text { Cost/ } \\
\text { QALYs }\end{array}$ & ICER \\
\hline Subgroup 2 (83) & $71,236.18$ & 25.2 & \multirow{2}{*}{$91,376.59$} & \multirow{2}{*}{8.4} & 2826.83 & \multirow{2}{*}{$10,878.10$} \\
\hline Subgroup 1 (39) & $162,612.77$ & 33.6 & & & 4839.67 & \\
\hline
\end{tabular}

(ICER—incremental cost-effectivity ratio, QALY—quality adjusted life years).

\section{Discussion}

Prevention of haemophilic arthropathy and improvement of QoL are still the main goals of hemophilia care. This approach was started in the early 1960-1970s, when available pd CFC provided effective bleeding control. The next great success was connected to the advent of the continuously enlarging scale of recombinant products with the possibility of increased dosage, in prophylactic regimen, accepting that prophylactic replacement is the standard of care, and at least $1 \%$ of FVIII or IX level has to be reached in order to assure zero bleeds. In recent years, the landscape of therapeutic products has changed, with the introduction of novel extended half-life (EHL) products, making it possible to reach a more generous goal of minimum 3-5\% plasma FVIII/ FIX activity, mandatory to prevent silent spontaneous joint bleeding, unavoidable with lower levels [17-20].

All these revolutionary innovative changes have been achieved at the expense of a considerable increase of the costs. At the same time, in the real life of the majority of $\mathrm{PwH}$ in the world, it became evident that lack of an optimal, adequate replacement therapy implies a great burden of secondary morbidity, morbidity that also generates high costs in the detriment of the quality of life [21,22]. The decisive role of the early start of prophylaxis, like primary prophylaxis, is also largely accepted: "one bleed is too much", as it starts the damaging action on the synovium and endochondral structure, initiating the chronic hemarthropathy, vulnerable for recurrent bleeding, even in the situation of late introduced prophylaxis [17]. 
Therefore, HTA agencies in cooperation with caregivers and decision makers started to evaluate, in a proper manner, the cost-effectiveness and cost-utility of PR, the only modality of long-term control of the disease for restoring health over a long period of time. A new vision of evaluation of cost-effectiveness, taking in account also the patient's perspective over the whole life, suggested that "treatment for life-prophylaxis in hemophilia is more effective than on demand in a cost-utility model" [16,22].

These were the reasons to undertake this PRO model of observational survey aiming at receiving a snapshot of information about the medical, psychosocial condition of our patients, their treatment and economic impact; we compared our results with correspondent outcomes from other European countries [23-27].

Our total real annual costs per patients were 74,192.4€; they were lower than those reported in the EU 5 countries with highest economic performances (France-196,117.00, Germany-319,024.00, Italy-220,344.00, Spain-173,771.00, and UK-129,363.00€). Our direct medical costs represented $92.83 \%$ of the total costs, lower than in Germany $(97,80 \%)$, Italy $(96.3 \%)$, and France $(95.80 \%)$. The main cost drivers were the expenses for CFC, representing in the whole group $98.58 \%$ of the direct costs and $91.5 \%$ of the total costs. Comparing the data of the two subgroups, it is evident that in subgroup 2 only $88.39 \%$ vs. $97.43 \%$ in subgroup 1 represented CFC costs; that means that secondary costs were 2 times higher in subgroup 2 . The indirect non-medical costs $(7.17 \%)$ were significantly higher than in EU 5 countries (1.59-5.5\%), but also higher than in Hungary and Bulgaria, expressing the high burden of costs due to secondary hemophilia treatment related morbidity [24-27].

ICER, highly linked to QoL parameters and dependent on the QALYs, with its value in the present situation of our GDP, highly supports the affordability of continuing prophylactic replacement in all severe forms of hemophilia, in patients of more than 18 years of age. It matches with the results of the comprehensive analysis performed on world level by Stonebraker [28] and in Europe by O'Mahoney [29,30], assessing our country on the last position in EU under our economic affordability. In a scenario based on the correction of CFC costs, adjusting them to BW, the data are revealing significantly higher CFC costs, however the assessment of ICER proved that the available prophylactic replacement of our present subgroup 1 will be affordable also in a time when it reaches adulthood.

Our results underscore the wide variety of costs that accompany a rare disease like hemophilia and the substantial economic burden carried by patients, caregivers, healthcare systems and economic potential of the country. The gold standard for evidence generating data for health interventions is represented by the randomized controlled trials, however, these are very difficult to be undertaken in the field of rare disorders; the limited size of patient population becomes even lower in the situation of multiple alternative therapeutic measures, like in the case of hemophilia [31-33]. We are aware that cost-effectiveness evaluations are confronted with many limitations, subject of disputes and controversies: choice of QALYs or DALYs (disability adjusted life years), arbitrary decided threshold for reimbursement, different among countries, generally accepting $<2-3 \mathrm{GDP} /$ capita/year, societal value having an important role in the decision, subjective perception of QoL, impacting the QALYs, insufficient transparency of the mathematical model used in the calculus of ICER and time inconsistencies in the evaluation, with very different results dependent on the time horizon taken into consideration (short term-one year, childhood or long-term 30-40 years, life-long) [9,10,23,34].

Some of these could be unavoidable. The important differences met in the reported data in the literature, even for the same country, are also due to the range of costs taken into consideration, the source of information, and the changes occurred over time $[24,25,27]$. In order to obtain more reliable results, we tried to use precise local data on healthcare costs from our institutions, cost of the medicines and social support assured in our country. We also decided to use the model of calculations for lifelong ICER, taking into account the average of life expectancy in males in our country, discounting it for PwH. Beside the real costs, we also calculated BW adjusted costs for CFC for more accurate comparative parameters in order to have a prediction of the affordability for the maintenance of prophylaxis for subgroup 1 in their adulthood. 
Despite of all these precautions, our study has some limits, the source of bias in the interpretation of the results in the subgroups 1 and 2 being the important difference between age of the patients, treatment history, body weight, all impacting the dosage and implicitly the costs of medication, the most important budget driver, the differences of the distribution of HA, HB and $\mathrm{vWD}$, with differential burden of disease and non-inclusion of bloodborne infections, hepatitis B and C, both with considerable budget consumption. Translating our costs/capita/year on national level could overestimate the consumption, as in our region a comprehensive multi-institutional approach of patients is set in place with the largest orthopedic and surgery centers for hemophilia, where $\mathrm{PwH}$ from all over the country are addressed [27,29].

\section{Conclusions}

Our study supported the cost-effectiveness of prophylactic replacement in hemophilia. The early introduction will prevent the secondary joint morbidity with all its deleterious consequences; the late introduction will slow down the dramatic evolution of already installed arthropathy with medical risks and social burden.

Author Contributions: Conceptualization, P.S. and B.V.; methodology, P.S.; M.S.; T.S.A.; software, P.S.; validation, B.V., M.S. and T.S.A..; formal analysis, C.E.U.; A.K.; investigation, P.S.; M.S.; C.E.U. and D.A.; data curation, M.S. and C.E.U.; writing — original draft preparation, P.S.; writing - review and editing, B.V. and T.S.A.; visualization, M.S.; A.T.; C.J. and J.M.P.; supervision, B.V.; J.M.P. and T.S.A.; project administration, M.S. and T.S.A. All authors have read and agreed to the published version of the manuscript.

Funding: This research received no external funding.

Acknowledgments: The investigators thank to Romanian Hemophilia Association and to the patients who participated in the study.

Conflicts of Interest: The authors declare no conflict of interest.

\section{References}

1. Mannucci, P.M. Hemophilia therapy: The future has begun. Haematologica 2020, 105, 545-553. [CrossRef]

2. Pelland-Marcotte, M.C.; Carcao, M.D. Hemophilia in a Changing Treatment Landscape. Hematol. Oncol. Clin. North Am. 2019, 33, 409-423. [CrossRef] [PubMed]

3. Makris, M.; Hermans, C. A golden age for Haemophilia treatment? Haemophilia 2018, 24, 175-176. [CrossRef] [PubMed]

4. Schramm, W. The history of haemophilia-A short review. Thromb. Res. 2014, 134, 4-9. [CrossRef] [PubMed]

5. Oldenburg, J.; Dolan, G.; Lemm, G. Haemophilia care then, now and in the future. Haemophilia 2009, 15, 2-7. [CrossRef] [PubMed]

6. Annual Global Survey 2018. Available online: http://www1.wfh.org/publications/files/pdf-1731.pdf (accessed on 15 October 2020).

7. Skinner, M.W. WFH: Closing the global gap-achieving optimal care. Haemophilia 2012, 18, 1-12. [CrossRef] [PubMed]

8. Gringeri, A.; Doralt, J.; Valentino, L.A.; Crea, R.; Reininger, A.J. An innovative outcome-based care and procurement model of hemophilia management. Expert Rev. Pharm. Outcomes Res. 2016, 16, 337-345. [CrossRef]

9. Schramm, W.; Royal, S.; Kroner, B.; Berntorp, E.; Giangrande, P.; Ludlam, C.; Gringeri, A.; Berger, K.; Szucs, T. Clinical outcomes and resource utilization associated with haemophilia care in Europe. Haemophilia 2002, 8, 33-43. [CrossRef]

10. Drummond, M.F.; Wilson, D.A.; Kanavos, P.; Ubel, P.; Rovira, J. Assessing the economic challenges posed by orphan drugs. Int. J. Technol. Assess. Health Care 2007, 23, 36-42. [CrossRef]

11. Skinner, M.W.; Chai-Adisaksopha, C.; Curtis, R.; Frick, N.; Nichol, M.; Noone, D.; O’Mahony, B.; Page, D.; Stonebraker, J.S.; Iorio, A. The Patient Reported Outcomes, Burdens and Experiences (PROBE) Project: Development and evaluation of a questionnaire assessing patient reported outcomes in people with haemophilia. Pilot Feasibility Stud. 2018, 27, 58. [CrossRef] 
12. O'Mahony, B.; Noone, D.; Tolley, K. An introduction to key concepts in health economics for haemophilia organizations. World Fed. Haemoph. 2010, 11, 1-19.

13. Mihailov, D.; Serban, M.; Lippert, B.; Schramm, W.; Arghirescu, S. Socio-Economic Aspects of Hemophilia Treatment in Romania. In 35th Hemophilia Symposium; Springer: Berlin, Germany, 2004.

14. Feldman, B.M. Issues in the measurement of quality of life in hemophilia. Rev. Bras. Hematol. Hemoter. 2013, 35, 299-301. [CrossRef] [PubMed]

15. Farrugia, A.; O'Mahony, B.; Cassar, J. Health technology assessment and haemophilia. Haemophilia 2012, 18, 152-157. [CrossRef] [PubMed]

16. Farrugia, A.; Cassar, J.; Kimber, M.C.; Bansal, M.; Fischer, K.; Auserswald, G.; O’Mahony, B.; Tolley, K.; Noone, D.; Balboni, S. Treatment for life for severe haemophilia A-A cost-utility model for prophylaxis vs. on-demand treatment. Haemophilia 2013, 19, e228-e238. [CrossRef]

17. Gringeri, A.; Ewenstein, B.; Reininger, A. The burden of bleeding in haemophilia: Is one bleed too many? Haemophilia 2014, 20, 459-463. [CrossRef]

18. Ar, M.C.; Balkan, C.; Kavaklı, K. Extended Half-Life Coagulation Factors: A New Era in the Management of Hemophilia Patients. Turk. J. Haematol. 2019, 36, 141-154. [CrossRef]

19. Amerine, L.B.; Chen, S.L.; Daniels, R.; Key, N.; Eckel, S.F.; Savage, S.W. Impact of an innovative blood factor stewardship program on drug expense and patient care. Am. J. Health Syst. Pharm. 2015, 72, 1579-1584. [CrossRef]

20. Mannucci, P.M. Miracle of haemophilia drugs: Personal views about a few main players. Haemophilia 2018, 24, 557-562. [CrossRef]

21. Schramm, W.; Gringeri, A.; Ljung, R.; Berger, K.; Crispin, A.; Bullinger, M.; Giangrande, P.L.; Von Mackensen, S.; Mantovani, L.G.; Nemes, L.; et al. Haemophilia care in Europe: The ESCHQoL study. Haemophilia 2012, 18, 729-737. [CrossRef]

22. Valente, M.; Cortesi, P.A.; Lassandro, G.; Mathew, P.; Pocoski, J.; Molinari, A.C.; Mantovani, L.G.; Giordano, P. Health economic models in hemophilia A and utility assumptions from a clinician's perspective. Pediatr. Blood Cancer 2015, 62, 1826-1831. [CrossRef]

23. Hyry, H.I.; Stern, A.D.; Cox, T.M.; Roos, J.C.P. Limits on use of health economic assessments for rare diseases. QJM Int. J. Med. 2014, 107, 241-245. [CrossRef] [PubMed]

24. Cavazza, M.Y.; Armeni, P.; De Santis, M.; López-Bastida, J.; Linertová, R.; Oliva-Moreno, J.; Serrano-Aguilar, P.; De-La-Paz, M.P.; Fattore, G.; Kanavos, P.; et al. Social/economic costs and quality of life in patients with haemophilia in Europe. Eur. J. Heal. Econ. 2016, 17, 53-65. [CrossRef]

25. O'Hara, J.; Hughes, D.; Camp, C.; Burke, T.; Carroll, L.; Diego, D.-A.G. The cost of severe haemophilia in Europe: The CHESS study. Orphanet J. Rare Dis. 2017, 12, 1-8. [CrossRef] [PubMed]

26. Henrard, S.; Devleesschauwer, B.; Beutels, P.; Callens, M.; De Smet, F.; Hermans, C.; Speybroeck, N. The health and economic burden of haemophilia in Belgium: A rare, expensive and challenging disease. Orphanet $J$. Rare Dis. 2014, 9, 39. [CrossRef] [PubMed]

27. Young, E. Socio-Economic Analysis: Impact of Haemophilia A in Romania; Roche: Basel, Switzerland, 2017; Available online: https:/www.roche.ro/content/dam/rochexx/roche-ro/roche_romania/ro_RO/files/studiiengleza/Impact_of_haemophilia_A_in_Romania.pdf (accessed on 15 October 2020).

28. Stonebraker, J.S.; Brooker, M.; Amand, R.E.; Farrugia, A.; Srivastava, A. A study of reported factor VIII use around the world. Haemophilia 2010, 16, 33-46. [CrossRef] [PubMed]

29. O'Mahony, B.; Noone, D.; Giangrande, P.L.; Prihodova, L. Haemophilia care in Europe-A survey of 35 countries. Haemophilia 2013, 19, e239-e247. [CrossRef] [PubMed]

30. O'Mahony, B.; Noone, D.; Giangrande, P.L.; Prihodova, L. Haemophilia care in Europe: A survey of 19 countries. Haemophilia 2011, 17, 35-40. [CrossRef]

31. Gringeri, A.; Lundin, B.; von Mackensen, S.; Mantovani, L.; Mannucci, P.M. A randomized clinical trial of prophylaxis in children with hemophilia A (the ESPRIT Study). J. Thromb. Haemost. 2011, 9, 700-710. [CrossRef]

32. Manco-Johnson, M.J.; Kempton, C.L.; Reding, M.T.; Lissitchkov, T.; Goranov, S.; Gercheva, L.; Rusen, L.; Ghinea, M.; Uscătescu, V.; Rescia, V.; et al. Randomized, controlled, parallel-group trial of routine prophylaxis vs. on-demand treatment with sucrose-formulated recombinant factor VIII in adults with severe hemophilia A (SPINART). J. Thromb. Haemost. 2013, 11, 1119-1127. [CrossRef] 
33. Tagliaferri, A.; Feola, G.; Molinari, A.C.; Santoro, C.; Rivolta, G.F.; Cultrera, D.B.; Gagliano, F.; Zanon, E.; Mancuso, M.E.; Valdré, L.; et al. Benefits of prophylaxis versus on-demand treatment in adolescents and adults with severe haemophilia A: The POTTER study. Thromb. Haemost. 2015, 114, 35-45. [CrossRef]

34. Drummond, M.F. Challenges in the economic evaluation of orphan drugs. Eurohealth 2008, 14, 16-17.

Publisher's Note: MDPI stays neutral with regard to jurisdictional claims in published maps and institutional affiliations.

(C) 2020 by the authors. Licensee MDPI, Basel, Switzerland. This article is an open access article distributed under the terms and conditions of the Creative Commons Attribution (CC BY) license (http://creativecommons.org/licenses/by/4.0/). 